\title{
Myocardial Infarction Following t-PA for Acute Stroke
}

\author{
M. Mehdiratta, C. Murphy, A. Al-Harthi, P.A. Teal
}

\begin{abstract}
Background and Purpose: Complications of intravenous (IV) thrombolysis with tissue plasminogen activator (t-PA) for acute stroke are commonly related to hemorrhage, anaphylaxis, or arterial re-occlusion. Embolic complications of t-PA are beginning to be recognized with increased use of t-PA for acute ischemic stroke. We hypothesize that disruption of intra-cardiac thrombus may result in myocardial infarction (MI) after use of t-PA for acute ischemic stroke. Summary of Cases: We describe three cases of acute MI immediately following IV t-PA infusion for acute stroke. In patient \#1 apical thrombus was visualized on cardiac echocardiogram accounting for the MI after t-PA for acute stroke. Patient \#2 had fresh thrombus seen on cardiac catherization after use of t-PA for acute stroke. Patient \#3 developed a significant troponin rise 15 hours after the t-PA for stroke infusion with an echocardiogram revealing new wall motion abnormalities. Patient \# 1 and \#2 died secondary to multi-organ failure. Discussion: Acute MI immediately following t-PA treatment for stroke is a rare but serious complication. The disruption of intra-cardiac thrombus and subsequent embolization to the coronary arteries may be an important mechanism in the development of MI after t-PA treatment for acute ischemic stroke.
\end{abstract}

RÉSUMÉ: Infarctus du myocarde suite à l'administration de tPA pour un accident vasculaire cérébral aigu. Contexte et objectif : Les complications de la thrombolyse intaveineuse au moyen de l'activateur du plasminogène tissulaire (tPA) dans l'accident vasculaire cérébral aigu (AVCA) sont généralement reliées à l'hémorragie, à l'anaphylaxie ou à la réocclusion artérielle. Les complications emboliques de l'administration de tPA commencent à être reconnues depuis que le tPA est utilisé plus fréquemment pour traiter l'AVCA. Nous avons émis l'hypothèse que la perturbation d'un caillot intracardiaque peut provoquer un infarctus du myocarde (IM) suite à l'administration de tPA pour le traitement d'un AVCA ischémique. Sommaire des observations : Nous décrivons trois patients qui ont subi un IM immédiatement après l'administration IV de tPA pour le traitement d'un AVCA. Chez le patient \#1, l'échocardiogramme a démontré la présence d'un thrombus apical expliquant l'IM après l'administration de tPA pour traiter un AVCA. Le cathétérisme cardiaque a montré que le patient \#2 était porteur d'un thrombus frais suite à l'administration de tPA pour un AVCA. Le patient \#3 a présenté une élévation significative de la troponine 15 heures après l'infusion de tPA pour un AVCA et l'échocardiogramme a révélé de nouvelles anomalies de la motilité de la paroi cardiaque. Les patients \#1 et \#2 sont décédés de défaillance multiviscérale. Discussion : L'IM immédiatement après l'administration de tPA pour un AVC est une complication rare, mais grave. La perturbation d'un thrombus intracardiaque et son embolisation subséquente à une artère coronaire peut jouer un rôle important dans la genèse d'un IM après l'administration de tPA pour traiter un AVCA ischémique.

Can. J. Neurol. Sci. 2007; 34: 417-420

Complications of intravenous (IV) tissue plasminogen activator (t-PA) for acute ischemic stroke are usually limited to hemorrhage and allergic type reactions. ${ }^{1}$ A National Institute of Neurological Disorders (NINDS) study revealed a $6.4 \%$ overall hemorrhage rate in patients treated with IV t-PA for acute ischemic stroke. ${ }^{2}$ Allergic reactions, such as anaphylaxis, laryngeal edema, orolingual angioedema, rash and urticaria have also been reported. ${ }^{3}$

The cardiology literature contains many cases of systemic and cerebral embolization following administration of t-PA for myocardial infarction. ${ }^{4,5}$ These cases are thought to have occurred secondary to disruption of intra-cardiac thrombus by t-PA .
Recently, Meissner et al reported a case of myocardial infarction after the use of t-PA for acute ischemic stroke. In this patient an atrial thrombus was detected on echocardiography. ${ }^{6}$

From the Beth Israel Deaconess Medical Center, Harvard Medical School (MM), Boston, MA, USA; Vancouver General Hospital (CM, AA, PT), University of British Columbia, Vancouver, B.C., Canada.

ReCEIVED JANUARY 17, 2007. ACCEPTED IN FINAL FORM MAY 27, 2007. Reprint requests to: Manu Mehdiratta, Beth Israel Deaconess Medical Center, Stroke Division, 330 Brookline Avenue, Palmer 127, Boston, MA, 02215, USA. 
The patient did not survive despite intensive medical efforts. In another case report of embolization, a patient was found to have had recurrent cerebral embolization of thrombus following treatment with IV t-PA for acute ischemic stroke. Using twodimensional echocardiography, the patient was found to have an intra-cardiac thrombus. ${ }^{7}$ It was thought that disruption of intracardiac thrombus by t-PA and secondary embolization was the likely mechanism in both cases.

We describe three cases of myocardial infarction (MI) within 15 hours of administration of IV t-PA for acute stroke. We hypothesize that treatment with IV t-PA may result in disruption of intra-cardiac clot with subsequent embolization to the coronary arteries, resulting in myocardial infarction.

\section{CASe Reports}

Patient 1: A 65-year-old right handed Japanese woman with a history of hypertension presented to the emergency department with sudden onset left sided weakness. She had evidence of mild left sided neglect, right gaze preference and left hemiparesis. A computed tomogram (CT) revealed a hyperdense right middle cerebral artery (MCA). There was insular involvement, with loss of the insular ribbon and lentiform nucleus on the right. Baseline electrocardiogram (ECG) revealed only left ventricular hypertrophy ( $\mathrm{LVH})$ with left axis deviation with no evidence of ischemia. She was diagnosed with a right MCA stroke syndrome with an unclear mechanism and received IV t-PA at 120 minutes following stroke onset.

Fifteen minutes following the end of the IV t-PA infusion, the patient had a sudden loss of consciousness and difficulty with respirations. At that time her BP was 67/43, with a HR of 43 . She had symmetric pulses and no tongue edema was noted. Pupils were $2 \mathrm{~mm}$ and reactive to light. There was no eye opening to pain and no verbal output. There was no movement on the right side to pain and the left side was noted to be moving spontaneously. The patient then developed complete heart block followed by 15 seconds of asystole. She received $0.1 \mathrm{mg}$ epinephrine and was intubated, following which her BP and HR normalized. Stat CT scan revealed no hemorrhage. ECG revealed ST segment elevation in the lateral and posterior leads. Troponin- $T$ on admission was $<0.1$. Approximately 20 minutes later, the patient spontaneously aroused and her neurological exam revealed left hemiparesis with visuospatial neglect as noted on initial presentation. It was thought that her decreased level of consciousness was due to hypoperfusion associated with cardiogenic shock.

She was diagnosed with an acute inferior MI following a troponin-T rise to 35.07 at 24 hours and ECG changes as described above. The patient was treated with ASA only. Echocardiogram revealed an apical thrombus that was $1 \times 1 \mathrm{~cm}$ in diameter (Figure 1). She had a normal LA and LV size. There was severe LV dysfunction with an estimated ejection fraction (EF) of $<20 \%$. There were no vegetations seen on the cardiac valves. Within 24 hours she had only mild left sided weakness and no neglect. She was started on heparin 24 hours after t-PA but continued to have embolic strokes in multiple vascular distributions. She developed acute renal failure, congestive heart failure (CHF) and pneumonia and subsequently died from respiratory failure two weeks after stroke onset.

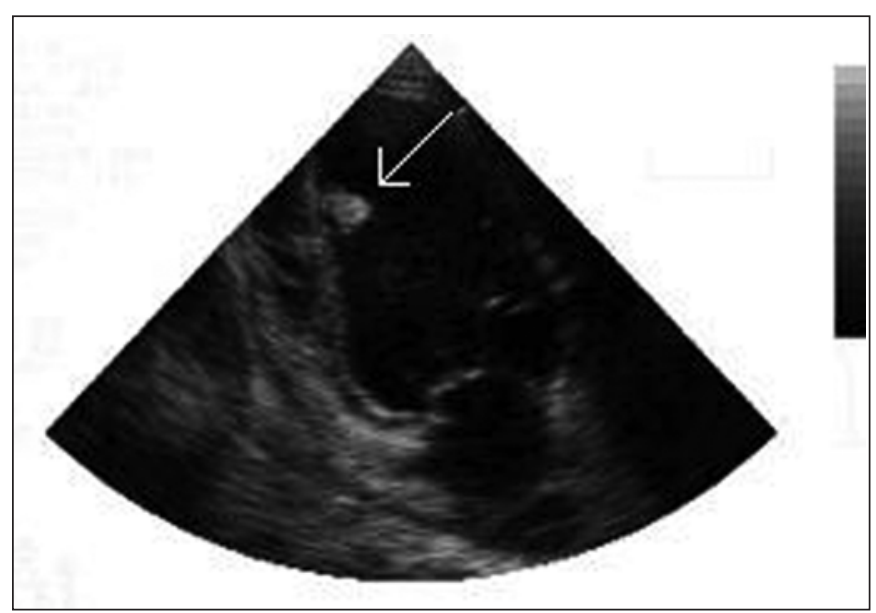

Figure 1: 1 X 1 apical clot (Case 1).

Patient 2: An 81-year-old woman presented to the emergency department with sudden onset right-sided weakness and language disturbance. She presented in atrial fibrillation. Neurological examination revealed a non-fluent aphasia with dense right hemiplegia and a right homonymous hemianopsia. CT revealed a hyperdense left MCA. She did have evidence of blurring of the insular ribbon and loss of the lentiform nucleus. Baseline ECG revealed atrial fibrillation, but no ischemic changes were seen. The patient was diagnosed with a left MCA stroke syndrome secondary to atrial fibrillation and received IV t-PA 105 minutes after the onset of her neurological symptoms.

She received a bolus of IV t-PA as per protocol and was started on the standard infusion. Ten minutes into the infusion of IV t-PA, she became unresponsive and the cardiac monitor revealed severe bradycardia with a HR of 35 and she was hypotensive. Neurological examination revealed that she was unresponsive to voice, her pupils were $3 \mathrm{~mm}$, equal and reactive and she withdrew to pain in the left arm and leg only. An ECG at that time revealed dramatic ST depression in the inferior leads and $2 \mathrm{~mm}$ of ST elevation in AVL. Troponin-T on admission was $<0.1$.

The coronary care unit (CCU) was called and she was intubated. She then developed pulseless electrical activity and a prolonged resuscitation ensued complicated by recurrent VT requiring defibrillation and epinephrine and atropine. The patient was stabilized and an urgent CT revealed no hemorrhage. The ECG was in keeping with an acute coronary syndrome. She underwent coronary angiography which revealed $100 \%$ occlusion of the left anterior descending (LAD) and circumflex coronary arteries with fresh thrombus or thrombus on top of a ruptured plaque, though this was considered less likely given the appearance (Figure 2). She underwent primary coronary angioplasty and stenting to the LAD and circumflex arteries. A transthoracic echo done the next day revealed no evidence of 


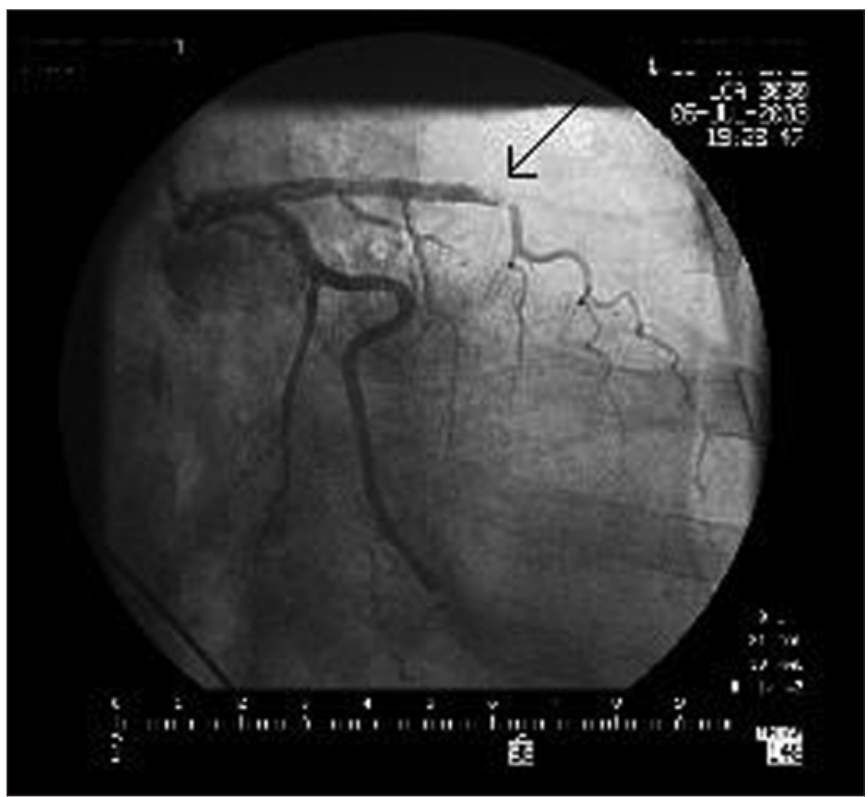

Figure 2: Coronary Angiography showing fresh clot in the LAD (Case 2).

cardiac thrombus and her ejection fraction was found to be $35 \%$. Through the next 24 hours she required increasing doses of vasopressors and later died of complications related to multisystem organ failure.

Patient 3: A 75-year-old right-handed Asian woman with a history of hypertension and hypercholesterolemia presented to the emergency department with sudden onset left sided weakness and slurred speech. She presented in atrial fibrillation and neurological examination revealed left sided neglect with a right gaze preference and evidence of a left homonymous hemianopsia. She had a dense left hemiplegia. She was noted to have decreased sensation to pinprick on the left side of her body. $\mathrm{CT}$ revealed a hyperdense right MCA with loss of the insular ribbon and lentiform nucleus on the right. Troponin- $\mathrm{T}$ on admission was $<0.1$. She was diagnosed with an acute right MCA stroke secondary to atrial fibrillation and received IV t-PA 170 minutes after onset of her stroke.

Fifteen hours after the t-PA infusion, she developed rapid atrial fibrillation with a HR of 160 . This was controlled with metoprolol but her troponin was elevated to 2.62 and ECG revealed anterolateral T-wave inversion and ST segment elevation. This was thought to be secondary to ischemia, but diagnostic angiography revealed normal coronary arteries. Echocardiogram revealed probable regional wall abnormalities without cardiac thrombus, likely arising from cardioembolic MI. The mechanism of myocardial injury was postulated to be thrombolytic-mediated embolization of thrombus to the coronary arteries.

\section{DISCUSSION}

We report 3 cases of myocardial infarction occurring immediately following IV t-PA for acute ischemic stroke. We suspect that systemic thrombolysis with IV t-PA contributed to fragmentation and subsequent coronary embolization of intracardiac thrombus.

Cardiac thrombus in the presence of acute ischemic stroke is a relatively rare occurrence. In one study, it was found that cardiac thrombus was present in only 5 of 183 patients $(2.7 \%)$ given IV t-PA for acute ischemic stroke using transesophageal echocardiography (TEE). In the patients who did have a cardiac thrombus identified, no patients had evidence of early systemic, coronary or cerebral embolization following the use of IV t-PA. However, one patient did develop late recurrent cerebral embolization. ${ }^{8}$ This suggests that cardiac thrombus should not be a contraindication for use of IV t-PA in acute ischemic stroke since there is a very low risk of complication. Another group, however, has detected cardiac thrombus in up to $26 \%$ of consecutive patients admitted for work-up of TIA or ischemic stroke by using TEE. Many of the patients in this study were over the age of 75 , perhaps accounting for the higher incidence of intracardiac thrombus. ${ }^{9}$ The incidence of embolization following the use of IV t-PA in this group was not studied.

There are other mechanisms by which stroke may have contributed to disruption of cardiovascular physiology in these patients. Strokes involving the insular cortex have been associated with the development of arrhythmias and death. ${ }^{10}$ This is thought to be secondary to the role of the insular cortex in autonomic regulation. All three of our patients had some degree of insular involvement on their initial CT scans. However, this mechanism of cardiac disturbance is less likely in our group of patients given the fact that there was no documented newonset arrhythmia found, despite 24-hour cardiac monitoring. In addition, intracardiac and intracoronary thrombus was seen in two of the three patients, suggesting an embolic mechanism. Another mechanism could have been concurrent MI and stroke not related to the use of t-PA. This is unlikely given the fact that in this case series all of the myocardial infarcts occurred within 24 hours of receiving IV t-PA and none of the patients had symptoms or signs of impending myocardial infarction on admission. In addition, the MI followed the start of the t-PA infusion by only 10 minutes and 75 minutes respectively in cases 1 and 2 .

Other etiologies to consider in patients with concurrent stroke and MI are aortic dissection, large vessel arteritis, endocarditis and in younger patients the use of drugs such as cocaine and amphetamines. These etiologies were considered and were not found in our patients.

In conclusion, these cases illustrate that the administration of t-PA may result in fragmentation of intra-cardiac thrombus with subsequent embolization to the coronary arteries resulting in MI. As the use of t-PA in acute ischemic stroke increases, it will be important to recognize the potential for embolic complications so that necessary diagnostic and treatment options can be pursued in a timely manner. 


\section{REFERENCES}

1. Compendium of Pharmaceuticals and Specialties, 2004. Canadian Pharmacists Association. 2004.

2. National Institute of Neurological Disorders and Stroke rt-PA Study Group. Tissue Plasminogen Activator for Acute Ischemic Stroke. N Eng J Med. 1995;333(24): 1581-7.

3. Hill MD, Lye T, Moss H, Barber PA, Demchuk AM, Newcommon $\mathrm{NJ}$, et al. Hemi-orolingual angioedema and ACE inhibition after alteplase treatment of stroke. Neurology. 2003;60(9): 1525-7.

4. Stafford PJ, Strachan CJ, Vincent R, Chamberlain DA: Multiple microemboli after disintegration of clot during thrombolyis for acute myocardial infarction. Br Med J. 1989; 299:1310-12.

5. Chang GY. An ischemic stroke during intravenous recombinant tissue plasminogen activator infusion for evolving myocardial infarction. Eur J Neurology. 2001; 8: 267-8.

6. Meissner W, Lempert T, Saeuberlich-Knigge S, Bocksch W, Pape U-F. Fatal Embolic Myocardial Infarction after Systemic Thrombolysis for Stroke. Cerebrovasc Dis. 2006;22:213-14.
7. Yasaka M, Yamaguchi T, Yonehara T, Moriyasu H. Recurrent embolization during intravenous administration of tissue plasminogen activator in acute cardioembolic stroke. A case report. Angiology. 1994;45(6):481-4.

8. Derex L, Nighoghossian N, Perinetti M, Honnorat J, Trouillas P. Thrombolytic therapy in acute ischemic stroke patients with cardiac thrombus. Neurology. 2001;57:2122-5.

9. Sen S, Laowatana S, Lima J, Oppenheimer SM: Risk factors for intracardiac thrombus in patients with recent ischaemic cerebrovascular events. J Neuol Neurosurg Psychiatry. 2004;75: 1421-5.

10. Abboud H, Berroir S, Labreuche J, Orjuela K. Amarenco P, GENIC Investigators. Insular involvement in brain infarction increases risk for cardiac arrhythmia and death. Ann Neurol. 2006 Apr;59(4):691-9. 